\title{
Design of Automatic Detection Model for Single-phase Earth Fault in Distribution Network
}

Yang Fan*, Guan Huanxin

\begin{abstract}
The current distribution network single-phase ground fault detection model knowledge expression is poor, its production process only based on the normal distribution network sample data, no single-phase ground fault data, did not make full use of a prior knowledge, resulting in low detection accuracy. The automatic detection model of single-phase earth fault of new distribution network is proposed. The fault characteristic vector is taken as the input vector, and the degree of matching between the input vector and the weight vector element is introduced as the second layer. The fault vector is used as the input vector, and the fault vector is used as the input vector. Node input, the second layer of the output as the third layer of the input, the model training, the output of the results of the distribution network is a single-phase ground fault detection results. The experimental results show that the proposed model has high detection accuracy.
\end{abstract}

Key words: Distribution network; single-phase earth fault; automation; detection

\section{Introduction}

Distribution network for the power system terminal, can directly to the user to provide electricity, its safe and stable operation for the entire power system key, a direct impact on the quality of power supply ${ }^{[1,2]}$. In recent years, with the rapid development of urban distribution network, more and more distribution lines, easily lead to distribution network single-phase ground fault, resulting in zero-sequence capacitor

Corresponding Author: Yang Fan, No. 2, Petrochemical Road, Hongwei District, Liaoyang City, Liaoning Province, China Petro. China Liaoyang Petrochemical Company Power Plant. E-mail: yfanan325@163.com

(College of Automation, Shenyang Institute of Technology, Shenyang 111003) current increases, long hours of work will lead to failure to expand into two or Multi-point grounding short circuit, resulting in equipment damage, can not guarantee the safe operation of power systems [3-5]. Therefore, it is of great significance to study a reliable automatic detection model of single-phase earth fault in distribution network, which has become a key research topic of related scholars ${ }^{[6]}$.

In [7], a single-phase earth fault detection method based on signal source method is proposed. After the single-phase earth fault occurs in the distribution network, the signal is transmitted to the system through the signal source device, and the alarm terminal is instructed by the detection terminal. In this paper, we propose a passive detection method, which is used to extract the fault feature quantity. According to the eigenvector, we can get the detection threshold, but the detection accuracy is not high. Fault detection. In this paper, a singlephase-to-ground fault detection method based on half-wave method is proposed, which assumes that the single-phase earth fault occurs, and the method is simple and accurate. When the phase voltage is close to the maximum value of the moment, when the fault occurs, the distribution network to the ground distributed capacitance on the use of ground point discharge, resulting in a significant transient voltage, through the completion of the single-phase ground fault detection, The method is simple, but it is susceptible to noise interference and affects the detection result. In [10], the single-phase earth fault detection method of distribution network based on impedance method is proposed. Firstly, the impedance of the measurement point Value to achieve fault detection, the cost is low, but the method is only suitable for simple circuit, cannot effectively detect the multi-branch distribution line single-phase ground fault.

Aiming at the shortcomings of the above methods, a new automatic fault detection model of single-phase earth fault is proposed. The fault feature vector is taken as the input vector, and the output result is the distribution network Single phase ground fault detection result. The experimental results show that the proposed model has high detection accuracy. 
2. Design o Automatic Detection Model for Single-phase Earth Fault in Distribution Network

\subsection{Extraction of single-phase ground fault charac- teristics of distribution network}

As shown in Figure 1, in the process of theoretical analysis through mathematical modeling, in order to facilitate the analysis, ignore the voltage drop in the line, select the three-phase complete three-phase symmetrical system as a Grid, all parameters are three symmetrical.

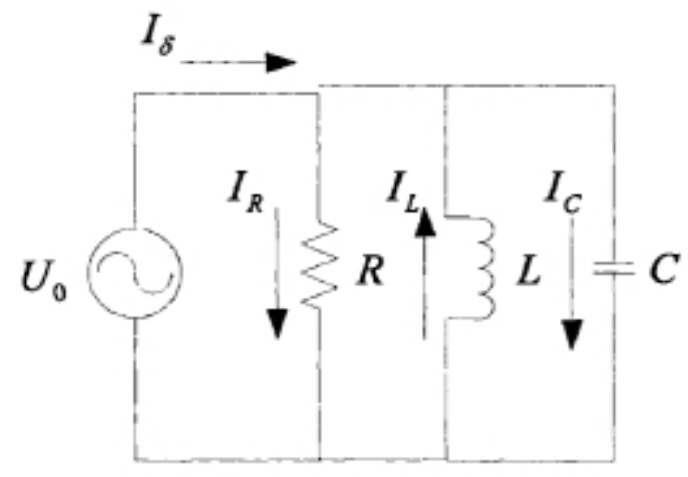

Figure 1 Simplified distribution system equivalent circuit

Fig. 1 Simplified equivalent circuit of distribution network system

In Figure 1, $U_{0}$ is used to describe the neutral point to ground potential; $L$ is used to describe the tuning inductance of the arc suppression coil; R mainly includes the ground leakage resistance $r_{0}$ and $r_{1}, R$ can be obtained by the following formula:

$$
R=\frac{1}{\frac{3}{r_{0}}+\frac{1}{r_{2}}}
$$

The capacitance in Figure 1 is the parallel equivalent of the relative capacitance, the formula is:

$$
C=3 C_{0}
$$

Which $C_{0}$ is used to describe the ground capacitance of each phase line.

Analysis of Figure 1 can be calculated by the distribution network single-phase ground fault current:

$$
I_{E}=\frac{U_{0}}{R}+j \omega C_{0}+\frac{U_{0}}{j \omega L}=I_{R}+j\left(I_{C}-I_{L}\right)
$$

Where ${ }^{j}$ is used to describe the imaginary part; $\omega$ is used to describe the frequency; ${ }^{R}$ is used to describe the real part of the single-phase ground fault current; the ${ }^{I_{C}}$ is used to describe the ground capacitance current of the distribution network; ${ }_{L}$ is used to describe the compensation current.

Assuming that the phase angle difference between the single-phase ground fault current and the neutral point displacement voltage $U_{0}$ of the distribution network is described by $\varphi$, the phase angle difference can be described as:

$$
\tan \varphi=\frac{\left(I_{c}-I_{L}\right) I_{R}}{I_{c} I_{\theta}} R C
$$

$\tan \varphi_{\text {is }}$ the characteristic of the single-phase ground fault of the distribution network, denoted as $x_{i}$, then the distribution vector of the single-phase ground fault of the distribution network can be described as $\left[x_{1}, x_{2}, \cdots, x_{N}\right]$.

\subsection{Single-phase earth fault automatic detection model}

In this section, the neural network method is used to design the single-phase earth fault detection model of distribution network, and the detailed analysis is given below.

The single-phase-to-ground fault feature vector is used as the input vector $\left[x_{1}, x_{2}, \cdots, x_{N}\right]$, use $\left[w_{1}, w_{2}, \cdots, w_{N}\right]$ and $\left[v_{1}, v_{2}, \cdots, v_{N}\right]$ to describe the random initialization of the connection weights. In order to enrich the input single-phase ground fault information, in the first layer of the neural network, the degree of matching di between the element $x_{i}$ and the element $w_{i}$ in the input vector is introduced. The formula is described as follows:

$$
d_{i}=\left(x_{i}-w_{i}\right)^{2}
$$

With $d_{i}$ as the input of the second layer node and the output of the second layer as the input of the third layer, the final output $y$ can be described as:

$$
y=\sum_{i=1}^{N} v_{i} f\left(d_{i}\right)=\sum_{i=1}^{N} v_{i} f\left[\left(x_{i}-w_{i}\right)^{2}\right]
$$

Where $f(\cdot)$ is used to describe the node functions of the second layer, and the radial basis functions are selected as follows:

$$
f(x, \sigma)=\exp \left(-\frac{\|x\|^{2}}{2 \sigma^{2}}\right)
$$

In the formula, $\sigma$ is used to describe the network learning rate. The smaller the $\sigma$ value, the steeper the function slope, the more the adjustment of the network weight, the faster the learning rate, but will affect the approximation accuracy. 
In order to measure the degree of matching between the detection model and the rest of the distribution network data, the matching threshold, $\lambda$ is introduced and will be compared with the established matching threshold, ${ }^{y}$ to obtain the matching error of the detection model:

$$
E=y-\lambda
$$

If the matching error $E>0$ for all input vectors $\left[x_{1}, x_{2}, \cdots, x_{N}\right]$, it is considered that the detection model can not match the distribution network data in its space, so it can be regarded as a monitor to detect non-spatial samples.

The automatic detection model of single-phase earth fault in distribution network in this section mainly includes training mode and detection mode.

In the training stage, firstly, the characteristic signals of the distribution network and the characteristic signals of the single-phase earth fault are collected, and the single-phase ground fault feature vector, $\left[x_{1}, x_{2}, \cdots, x_{N}\right]$ is obtained. It is regarded as the input of the automatic detection model. Failure of the automated detection model for training in the process, the use of regional training strateqies, as shown in Fiqure 2.

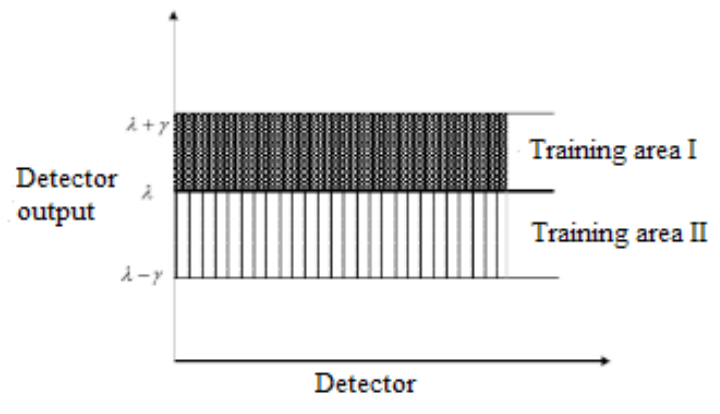

Figure 2 Regional training strategies for the model

Fig. 2 Detection model of regional training strategy

The training is divided into two cases. The first case is applicable to the single-phase ground fault characteristic signal of the distribution network. Corresponding to the training area I in Fig. 2, if $0<E<y$, the training of the automatic detection model is carried out by BP network training method reduce the error $E$ to complete; otherwise, not training.

The second case applies to the normal characteristics of the distribution network signal, and Figure 2 in the training area $\square$ corresponding, if- $y<E<0$, through the neural network method to increase the error $E$ to complete the automated detection model to carry out training.

Where $y$ is used to describe the boundary parameters, usually $0.1 \lambda$.
Using the above training process, the automated detection model can cover the entire non-occupied space through continuous learning and training through the existing normal distribution network and single-phase ground fault samples.

In the detection phase, the detection model is used to detect the single-phase earth fault of the distribution network. If $E<0$, the detection model is activated and the fault detection result can be obtained according to the statistical information of the detection model.

\section{Experimental results analysis}

\subsection{On-site experimental program}

The experiment selects one of the lines of a power supply office as a test line, and selects three singlephase-to-ground fault test points in the line. The distance between the large side of pole 1 and the outlet of the substation is $0.4 \mathrm{~km}$. Point 2 on the branch line of the 1.52 pole on the large side, and the substation outlet switch between the distance is $4.11 \mathrm{~km}$, the experimental point 3 in the branch line 1.19 pole on the large side, and the substation outlet switch between the distance is $2.23 \mathrm{~km}$ The

The equipment required for the experiment mainly includes high power resistance box, circuit breaker, isolating switch, voltage and current transformer, recorder, grounding resistance tester and grounding equipment. Distribution network single-phase ground fault automatic detection test interface shown in Figure 3.

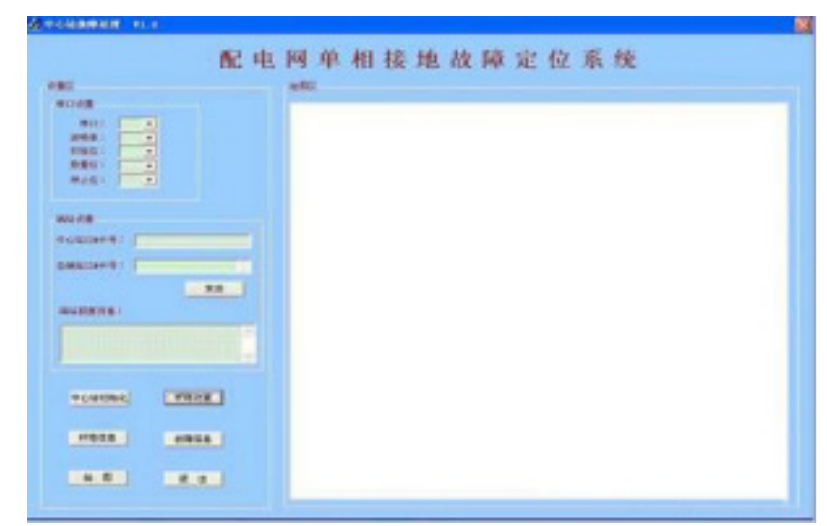

Figure 3 fault detection interface

Fig. 3 Fault detection interface

\subsection{Fault detection accuracy test}

In this paper, the half-wave model and the impedance model are used as a comparison to verify the effectiveness of the proposed method. Three models are used to test the single-phase ground fault. The number of correct tests, the number of false detections and the number of rejections of the three models are described in Table 1, where the number of times of refusal is the number of times the detection model does not perform the test.

Table 1 Comparison of three methods of detection re- 
sults

Table 1 Testing results of three methods

$\begin{array}{cccc}\text { Test model } & \begin{array}{c}\text { Present } \\ \text { model }\end{array} & \begin{array}{c}\text { Half - } \\ \text { wave } \\ \text { model }\end{array} & \begin{array}{c}\text { Impedance } \\ \text { model }\end{array}\end{array}$

\begin{tabular}{lccc}
$\begin{array}{l}\text { Number of correct } \\
\text { tests / times }\end{array}$ & 18 & 15 & 13 \\
$\begin{array}{l}\text { Number of false } \\
\text { detections / times }\end{array}$ & 0 & 2 & 4 \\
$\begin{array}{l}\text { Number of times of } \\
\text { refusal / time }\end{array}$ & 1 & 4 & 3 \\
$\begin{array}{l}\text { Total number of exper- } \\
\text { iments / times }\end{array}$ & 20 & 21 & 20 \\
\hline
\end{tabular}

Using the above experimental results, the correctness, the error rate and the rejection rate of the model, the impedance model and the half-wave model are obtained. The formula is described as follows:

$$
\text { Correctness }=\frac{\text { Number of correct tests }}{\text { Number of experiments in this way }} \times 100 \%
$$

Error rate $=\frac{\text { Number of false detections }}{\text { Number of experiments in this way }} \times 100 \%$

Rejection rate $=\frac{\text { Number of times of refusal }}{\text { Number of experiments in this way }} \times 100 \%$

The correctness, the error rate and the rejection rate of the three models are obtained by the above formula. The comparison results are described in Table 2.

Table 2 Comparison of the correctness, misoperation rate and rejection rate of the three models

Table 2 Three kinds of model accuracy, misoperation and miss ratio comparison results

\begin{tabular}{cccc}
\hline Test Index & $\begin{array}{c}\text { Present } \\
\text { model }\end{array}$ & $\begin{array}{c}\text { Half }- \\
\text { wave } \\
\text { model }\end{array}$ & $\begin{array}{c}\text { Impedance } \\
\text { model }\end{array}$ \\
Correctness $/ \%$ & $90.00 \%$ & $71.43 \%$ & $65.00 \%$ \\
Rejection rate $/ \%$ & $5.00 \%$ & $19.05 \%$ & $15.00 \%$ \\
Error rate $\%$ & $0.00 \%$ & $9.52 \%$ & $20.00 \%$ \\
\hline
\end{tabular}

As shown in Table 2, it can be seen that the correctness of the detection of the single-phase earth fault of the distribution network is as high as $90 \%$, which is $18.57 \%$ higher than the detection rate of the half-wave model $71.43 \%$, which is higher than the detection accuracy of the impedance model $65 \%, 25 \%$ higher; the rejection rate of this model is only $5 \%$, which is $14.05 \%$ lower than that of the half - wave model. It is $10 \%$ lower than the $15 \%$ rejection rate of the impedance model. The false positive rate of present model is $0 \%$, which is $9.52 \%$ lower than that of the half-wave model. It is $20 \%$ lower than the $20 \%$ error rate of the impedance model. Therefore, present model has the highest accuracy for single-phase earth fault detection of distribution network.

In the fault detection accuracy test, the grounding resistance is adjusted to $50 \Omega, 100 \Omega, 150 \Omega$ and $300 \Omega$ respectively. On this basis, the present model, halfwave model and impedance model are used to detect the single-phase grounding fault of the distribution network. As shown in Table 3, the "l" on the left side of Table 3 is the correct number of tests, and the right side is the total number of experiments under certain conditions.

Table 3 different ground resistance under the three models of experimental results

Table 3 The three models under different grounding resistance results results

\begin{tabular}{ccccc}
\hline Model used & 50 & 100 & 150 & 300 \\
Present & $5 / 5$ & $5 / 5$ & $7 / 7$ & $4 / 5$ \\
model & & & & \\
$\begin{array}{c}\text { Half-wave } \\
\text { model }\end{array}$ & $4 / 5$ & $3 / 5$ & $4 / 7$ & $3 / 5$ \\
$\begin{array}{c}\text { Impedance } \\
\text { model }\end{array}$ & $2 / 5$ & $4 / 5$ & $3 / 7$ & $2 / 5$ \\
\hline
\end{tabular}

In Table 3, it can be seen that the correctness of the fault detection is higher than that of the half-wave model and the impedance model, and the performance of the method is verified by the different grounding resistance values.

\subsection{Single-phase-to-ground fault waveform analy- sis}

When the distribution network line appears single-phase ground fault, according to different grounding conditions will produce transient phenomena, the most significant phenomenon for the ground phase current mutation is very high, the experiment accordingly to determine whether there is single-phase ground fault.

Figure 4 describes the actual single-phase ground fault condition, Figure 5 to Figure 7, respectively, describes the model, half-wave model and impedance model of single-phase ground fault detection results.

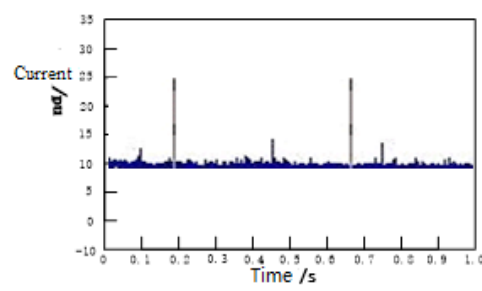


Figure 4 Actual single-phase ground fault condition

Fig. 4 The actual single-phase earth fault

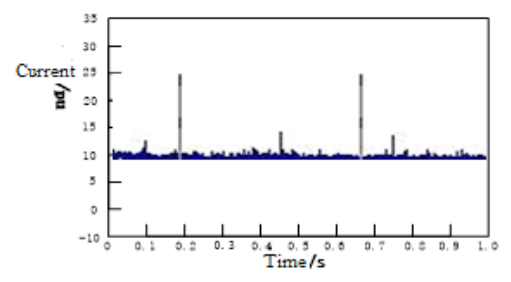

Figure 5 Present model single-phase ground fault detection results

Fig. 5 In this paper, models of single-fault grounding detection results

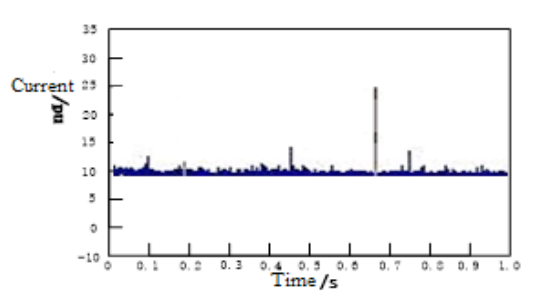

Figure 6 Half-wave model single-phase ground fault detection results

Fig. 6 Half wave model of single-phase grounding fault detection results

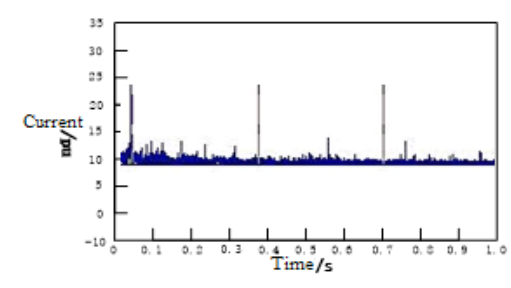

Figure 7 Impedance model single-phase ground fault detection results

Fig. 7 Impedance model of single-phase grounding fault detection results

It can be seen from Fig. 5 to Fig. 7 that the fault detection results obtained by using the model in this paper are in good agreement with the actual results, which can accurately detect the two faults of single-phase grounding in the distribution network, and the halfwave model only detects A single-phase ground fault, impedance model, although the detection of two single-phase ground fault, but a false test of a fault, indicating that the model of the highest detection performance.

\section{Conclusion}

In this paper, a new automatic fault detection model for single-phase earth fault of distribution network is proposed. The single-phase earth fault feature of distribution network is extracted and the automatic detection model of single-phase earth fault of distribution network is designed. The fault feature vector is taken as the input vector. Regional training strategies to train the model, through the existing distribution network normal and single-phase ground fault samples, continuous learning and training to cover the entire non-occupied space. The detection model is activated by the trained model, and if the matching error is less than zero, the detection model is activated and the single-phase ground fault detection result of the distribution network can be output according to the statistical information of the detection model. The experimental results show that the proposed model has high detection accuracy.

\section{References}

[1] Guo Shanghua, Song Guobing, Zhang We, et al. A Self-Healing Scheme for Single-Phase Earth Fault Of Channelless Distribution Network [J]. Power, 2015,32 (8): 64-70.

GUO Shanghua, SONG Guobing, ZHANG Wei, et al. A Self-healing Solution of Single-phase Ground Fault for Distribution Network without Communication [J]. Distribution \& Utilization, 2015, 32 (8): 64-70.

[2] Kang Zhongjian, Liu Ruiying.Study on singlephase-to-ground fault location of distribution network based on impedance model feature matching [J]. Power Grid \& Clean Energy, 2015,31 (08): 40-46.

KANG Zhongjian, LIU Ruiying.A Fault Location Method for Single-Phase Grounding Fault in Distribution Network [J]. Advances of Power System \& Hydroelectric Engineering, 2015, 31 (08): 40-46.

[3] Wang Shibin, Shi Tongjun, Tang Quan.Study on approximation entropy algorithm in single-phase ground fault location [J]. Electrical Automation, 2014,36 (01): 91-93.

WANG Shi-bin, SHI Tong-jun, TANG Quan.Research on Approximate Entropy Algorithm for Single-phase Grounding Fault Location [J]. Electrical Automation, 2014,36 (01): 91-93.

[4] XU Ming-ming, XIAO Li-ye, LIN Liang-zhen.Study on single-phase fault fault location method of distribution line based on zero-mode traveling wave attenuation [J]. Journal of Electrical Engineering, 2015,30 (14): 397-404.

Xu Mingming, Xiao Liye, Lin Liangzhen.A Fault Location Method for the Single-phase-to-earth fault in Distribution System Based on the Attenuation Characteristic of Zero-mode Traveling Wave [J]. Transactions of China Electrotechnical Society, 2015, 30 (14): 397404. 
[5] Huang Chao-yi, Cai Jin-ing, Li Tian-you, et al. Adaptability Analysis of Single-phase Earth Fault Location in Distributed Access Network [J]. Electrical Technology, 2015,16 (7): 58-62.

Huang Chaoyi, Cai Jinding, Li Tianyou, et al. Adaptability Analysis of Single-phase Fault Location for Distribution Network with Generations [J]. Electrical Engineering, 2015, 16 (7): 58-62.

[6] WANG Bin, GENG Jian-zhao, DONG Xin-zhou.Extimate modeling of high-resistance grounding fault of distribution line based on dielectric breakdown principle [J]. Automation of Electric Power Systems, 2014,38 (12): 62-66.

WANG Bin, GENG Jianzhao, DONG Xinzhou.High-impedance Fault Modeling Based on Solid Dielectric Electrical Breakdown Theory [J]. Automation of Electric Power Systems, 2014, 38 (12): 62-66.

[7] Cong Wei, Tian Chong-zheng, ZHAO Yi-shu, et al. Fault Direction Components of Intelligent Distribution Network Based on Amplitude Comparison of Voltage Variation.[J]. Power System Automation, 2014,38 (15): 93-99.

CONG Wei, TIAN Chongwen, ZHAOYishu, et al.A Fault Directional Element Based on Voltage Variation Amplitude Comparison for Smart Distribution Network [J]. Automation of Electric Power Systems, 2014, 38
(15): 93-99.

[8] Li Guodong, Ge Leijiao, Liu Chuanghua, et al. Active distribution network PQMT consistent network detection platform construction [J]. Electrical drive, 2015,45 (12): 65-69.

LI Guo-dong, GE Lei-jiao, LIU Chuang-hua, et al.Consistent Detection Platform Construction of Active Distribution Network Power Quality Monitoring Terminal[J]. Electric Drive, 2015, 45 (12): 65-69.

[9] CAI Qi. Application of Multiwavelet Theory in Distribution Network Fault Line Selection [J]. Electronic Design Engineering, 2016,24 (08): 163-167.

CAI Qi.Research and application of multiwaves theory for the fault selection of phase-to-ground fault selection in distribution network [J]. Electronic Design Engineering, 2016, 24 (08): 163-167.

[10] WANG Jian-bo, SHAO Wen-quan, ZHANG Yanli, et al.[J]. Journal of Xi'an Engineering University, 2015,29 (5): 617-622. [J]. Journal of Xi'an Engineering University, 2015,29 (5): 617-622.

WANG Jianbo, SHAO Wenquan, ZHANG Yanli, et al.A fault type detection scheme for voltage sag based on differential-voltage [J]. Journal of Xi'an Polytechnic University, 2015,29 (5): 617-622. 